\title{
Game Analysis of Family Firm Innovation Decision - Taking BYD as an Example
}

\author{
Min Zhao ${ }^{1,2, a}$, Xin $\mathrm{Yao}^{3, \mathrm{~b}}$ \\ ${ }^{1}$ China National Institute of Standardization, Beijing 100191, China \\ ${ }^{2}$ Tsinghua University, Beijing 100083, China \\ ${ }^{3}$ CCPIT Commercial Sub-council, Beijing 100801, China \\ azhaomin@cnis.gov.cn, byaoxin@ccpit.org
}

Keywords: Family firm, Governance Structure, Game Analysis, BYD.

\begin{abstract}
Innovation is the soul of the survival and development of enterprises. Innovation decisionmaking is an important guarantee for the sustainable development of family firm. This paper intends to introduce game analysis into the family firm innovation field. It selects the evolutionary dynamic game model to analyze how to make decisions in family firms and how family leaders play a role in innovation decision-making. This article selects BYD's innovative decision to march into the car market in 2003 as a case to analyze how to make the innovation decision in the game.
\end{abstract}

\section{Introduction}

Governance structure is an important factor affecting the family firm innovation. A good governance structure can ensure the effectiveness, sustainability and efficiency of family firms. Whether the decision-making mechanism is smooth is an important indicator of the governance structure [1]. As a leader in new energy vehicles, BYD started out in the battery industry and resolutely entered the automotive industry in 2003. This innovative decision is an important turning point in BYD's transformation and an important node in the success of BYD [2]. So, how does the innovative strategy for BYD's marching into the car market come into being? How can game participants influence innovation decision-making during the game?

\section{Game Model Selection}

The traditional game analysis is based on the complete rationality of all stakeholders, while the bounded rationality and incomplete information will affect the validity of traditional game analysis results. Evolutionary game breaks the strict assumption of the "rational" environment by the traditional game model. In 1973, the ecologist Maynard Smith \& Price put forward the theory of biological evolution and traditional game theory. Evolutionary game theory based on Darwin's theory of biological evolution, and studies the game activities of game participants repeated and adjusted in the game community. Due to the limited rationality of game participants, each player in the game will not find the optimal equilibrium point in every game. They will imitate and improve during the game in the process of the game. After long-term learning, imitation, readjustment, and improvement, all the game participates in one of the most favorable strategies in the final region to achieve equilibrium. Because the evolutionary game theory is closer to the reality of the state of decision-making, it has been widely used. Replicator dynamics is the most widely used model in evolutionary game theory [3]. This paper chooses the imitator dynamic model to analyze the innovation decision-making mechanism in family firms.

\section{Innovation Strategy Game Analysis}

\subsection{Model Building}

Among the influencing factors of innovation decision-making, the governance structure has a significant impact on whether the family alliance owns the decision-making autonomy. The family 
equity involvement determines the family's control over the alliance. Family firm innovation decision-making has many different levels, and different innovation decision-making is actually an evolutionary process. To simplify, the game model divides the family firm innovation decisionmaking into two categories: one is to completely reject innovation and the other is to subvert innovation. Suppose there are two kinds of game groups in the innovation decision, one is the family group and the other is stakeholder. In the process of the game, all the players in both sides of the game adopt the pure strategy [4].

Take BYD's decision-making process in the automotive field as an example. BYD was in the heyday of the battery area, and into the automotive industry would face high threshold, high investment and high risk. Most of BYD's external investors tend to be conservative and oppose entering the car industry. The family group represented by the founder Wang Chuanfu tended to enter the automobile industry to achieve innovative development and strategic transformation. Therefore, the game model will be set to two types of innovation decisions: one is completely refused to enter the car field, focusing on the battery area; the other is fully into the automotive industry. Suppose there are only two kinds of game groups, one is the family group, represented by the founder Wang Chuanfu, and the other is the stakeholder group, represented by the external investors. The strategic space of two kinds of game groups is: $S_{f}=\left(s_{1}, s_{0}\right), S s=\left(s_{1}, s_{0}\right)$. Among them, $s_{1}$ means to enter the auto industry and $s_{0}$ means to veto a motion to enter the auto industry.

Table 1. BYD game matrix

\begin{tabular}{|c|c|c|c|}
\hline & & \multicolumn{2}{|c|}{ Stakeholder Group (s) } \\
\hline & & $\mathrm{s}_{1}$ & $\mathrm{~s}_{0}$ \\
\hline \multirow{2}{*}{ Family group (f) } & $\mathrm{s}_{1}$ & $\left(\mathrm{a}, \mathrm{a}^{\prime}\right)$ & $\left(\mathrm{c}, \mathrm{c}^{\prime}\right)$ \\
\cline { 2 - 4 } & $\mathrm{s}_{0}$ & $\left(\mathrm{~b}, \mathrm{~b}^{\prime}\right)$ & $\left(\mathrm{d}, \mathrm{d}^{\prime}\right)$ \\
\hline
\end{tabular}

In the game matrix, the $\mathrm{s}_{1}$ strategy is adopted by the family group represented by Wang Chuanfu, while the $\mathrm{s}_{0}$ strategy is adopted by the stakeholder groups represented by external investors. Two groups adopt inconsistency strategy. The gain of the family group $\mathrm{f}$ is $\mathrm{c}$ and the gain of the stakeholder group s is c'. The initial game state of the BYD game group is located in the region (c, $\left.\mathrm{c}^{\prime}\right)$ of the game matrix.

\subsection{Game Process and Model Analysis}

Suppose that in the initial stage of the innovation game, the equity of the family group with the proportion of $x$ choose the strategic $s_{1}$, and the other family groups with the proportion of 1 -x choose the strategic $s_{0}$. Other stakeholder groups with a share of ownership of $y$ choose a strategy $s_{1}$, and other stakeholder groups at a ratio of $1-y$ chooses $s_{0}$. The expected benefit of the family group selected strategy $s_{1}$ is $U_{s_{1}}$, and the expected benefit of the family group selected strategy $s_{0}$ is $U_{S_{0}}$. The average benefit of the family group (the mixed strategy benefit of the family group) is $U_{f}$. Then:

$$
\mathrm{U}_{\mathrm{f}}=\mathrm{x}[\mathrm{ay}+\mathrm{c}(1-\mathrm{y})]+(1-\mathrm{x})[\mathrm{by}+\mathrm{d}(1-\mathrm{y})]
$$

Construct a reproductive dynamic equations of the family group:

$$
\mathrm{F}(\mathrm{x})=\frac{\mathrm{d}_{\mathrm{x}}}{\mathrm{d}_{\mathrm{t}}}=\mathrm{x}\left(\mathrm{U}_{\mathrm{s}_{1}}-\mathrm{U}_{\mathrm{f}}\right)=\mathrm{x}(1-\mathrm{x})[(\mathrm{a}-\mathrm{b}) \mathrm{y}+(\mathrm{c}-\mathrm{d})(1-\mathrm{y})]
$$

In evolutionary game analysis, the speed and direction of game participants' learning are reflected in the replication of dynamic equations. When the value of replication dynamic equation is 0 , it implies that the speed of game player learning decreases to zero, indicating that the game has reached a relatively stable equilibrium at this time. Therefore, let $\mathrm{F}(\mathrm{x})=0$, so that $\mathrm{x}=0$ and $\mathrm{x}=1$ are two stable states of $\mathrm{x}$. However, not all of these two steady states are stable strategies (ESS) in evolutionary games. Because ESS requires a stable state must have anti-disturbance function, the first-order conditions to meet $\mathrm{F}^{\prime}(\mathrm{x})$ must be less than zero. Thus:

when $\mathrm{y}>\frac{\mathrm{d}-\mathrm{c}}{(\mathrm{a}-\mathrm{b})+(\mathrm{d}-\mathrm{c})},\left.\mathrm{F}^{\prime}(\mathrm{x})\right|_{\mathrm{X}=1}<0$, That is, $\mathrm{x}=1$ is ESS;
when $\mathrm{y}<\frac{\mathrm{d}-\mathrm{c}}{(\mathrm{a}-\mathrm{b})+(\mathrm{d}-\mathrm{c})},\left.\mathrm{F}^{\prime}(\mathrm{x})\right|_{\mathrm{X}=0}<0$, That is, $\mathrm{x}=0$ is ESS;
Similarly,

when $\mathrm{x}>\frac{\mathrm{d}^{\prime}-\mathrm{c}^{\prime}}{\left(\mathrm{a}^{\prime}-\mathrm{b}^{\prime}\right)+\left(\mathrm{d}^{\prime}-\mathrm{c}^{\prime}\right)},\left.\mathrm{F}^{\prime}(\mathrm{y})\right|_{y=1}<0$, That is, $\mathrm{y}=1$ is ESS; 
when $\mathrm{x}<\frac{\mathrm{d}^{\prime}-\mathrm{c}^{\prime}}{\left(\mathrm{a}^{\prime}-\mathrm{b}^{\prime}\right)+\left(\mathrm{d}^{\prime}-\mathrm{c}^{\prime}\right)},\left.\mathrm{F}^{\prime}(\mathrm{y})\right|_{y=0}<0$, That is, $\mathrm{y}=0$ is ESS;

At the initial stage of innovation game, Wang Chuanfu takes only $28 \%$ of the equity. But he also serves as chairman and President of BYD, and has a greater voice in decision-making and management. From the initial state of BYD's decision-making point of view, not only outsiders, many of the company executives also opposed the opposition $s_{1}$. The group against the $s_{1}$ innovation strategy is larger.

In the evolutionary game analysis of BYD's dabbling in the field of automobile, obviously did not reach a relatively stable equilibrium (ESS). According to the equilibrium evolution of the asymmetric replication dynamic game, when the game starts, there are more than $\frac{d^{\prime}-c^{\prime}}{\left(a^{\prime}-b^{\prime}\right)+\left(d^{\prime}-c^{\prime}\right)}$ of the family groups choose a complete innovation strategy to support the entry into the automotive industry, while the proportion of the stakeholder groups that choose a complete innovation strategy is far below $\frac{d-c}{(a-b)+(d-c)}$. The initial state is not balanced. At this time, the speed of learning and adjustment by both parties determines the final game equilibrium. As a $s_{1}$ strategic choice, Wang Chuanfu has the right to make decision and control. And as the founder of BYD, Wang Chuanfu has become the soul of the BYD. After experiencing the disruptions of some external investors, he persuaded a large number of family members and stakeholders. Over proportioning $\frac{d^{\prime}-c^{\prime}}{\left(a^{\prime}-b^{\prime}\right)+\left(d^{\prime}-c^{\prime}\right)}$ of the family group and over the ratio $\frac{d-c}{(a-b)+(d-c)}$ of the other stakeholders eventually choosed to support entering the automotive market. The game will converge to the evolutionary stable strategy $\left(x^{*}=1, y^{*}=1\right)$. In the end, BYD marched into the automotive market. In January 2003, BYD formally acquired 77\% stake in Xi'an Qinchuan Automobile Co. Ltd. and officially entered the automotive industry. BYD finally achieved strategic transformation of innovation.

\section{Summary}

Family firm decision-making patterns generally have the characteristics of speed and flexibility. Wang Chuanfu as the second largest shareholder, is both chairman and president of BYD. The coincidence of the decision layer and the executive layer simplifies the transmission of complex information, thus the information transfer between the two layers is more smooth. And the problem of information asymmetry and agent issues are less. At the same time, family members are linked by kinship or friend ties that provide a special kind of information delivery mechanism that enables quick and accurate collection of information at the decision-making level. In addition, the combination of decision-making and executive level will lead to greater execution.

As the soul of BYD, Wang Chuanfu not only maintains the control over BYD, but also maintains good communication with stakeholders. By virtue of his high sensitivity and insight to the trend of technological development, Wang Chuanfu persuaded a large number of family group and stakeholders and played an important role in the innovation game of BYD. Over proportioning $\frac{d^{\prime}-c^{\prime}}{\left(a^{\prime}-b^{\prime}\right)+\left(d^{\prime}-c^{\prime}\right)}$ of the family group and over the ratio $\frac{d-c}{(a-b)+(d-c)}$ of the other stakeholders eventually choosed to support entering the automotive market. Wang Chuanfu introduced BYD to the road to innovation.

This work is supported by Dean Foundation of China National Institute of Standardization (572018Y-5938).

\section{References}

[1]. Zonghui, Li Joshua, Daspit. Understanding family firm innovation heterogeneity: A typology of family governance and socioemotional wealth intentions. Journal of family firm management. Vol.6(2016), P103-121. 
[2]. Guo Yanqing, Shi Hongmei. Research on innovative ways in the development of BYD new energy vehicle. Management case study and review. Vol.2(2010) No.12, P469-478.

[3]. Liu Weibing, Wang Xian-jia. A Review on the design of evolutionary game theory. Management science and management, Vol.5(2008) No. 7601, P84-87 + 105.

[4]. Bian Wenxia. A study on the transformation of governance structure in family firm enterprisesa game analysis based on contractual theory of firm. Journal of Beijing Technology and Business University (Social Science Edition). Vol.6(2011) No.26, P58-64. 